\section{International Scientific Journal Theoretical \& Applied Science}

p-ISSN: 2308-4944 (print) e-ISSN: 2409-0085 (online)

Year: $2018 \quad$ Issue: 02 Volume: 58

Published: $28.02 .2018 \quad$ http://T-Science.org
Sergey Alexandrovich Mishchik

Associate Professor, Candidate of Pedagogical Science,

Academician of International Academy TAS, Assistant professor Department of Physics,

State Maritime University Admiral Ushakov, Russia, sergei_mishik@mail.ru

SECTION 21. Pedagogy. Psychology. Innovation in Education

\title{
SYSTEMIC PROBLEMS OF ELECTROMAGNETIC INDUCTION OF APPLIED PHYSICS MARITIME FLOT OF PEDAGOGOMETRIC ANALYSIS
}

\begin{abstract}
The basic principles of the system problems of electromagnetic induction in applied physics Navy pedagogometric analysis of the formation of mathematical models of learning activities about the nature of achieving the criteria of life, cycling, systemsness and phasing, which form a basic cell of the educational space, as well as prima nenie twelve pointed star Ertsgammy relatively presentation ertsgamming principle which determines the foundations pedagogometric through forming substantive methods of hyper-space professional life, psychological and educational activity theory, psycho-pedagogical system analysis and the theory of the formation of mental actions.

Key words: pedagogometric, vital activity, cyclicity, system, phase, star Erzgammy, electromagnetic induction, applied physics, marine fleet.

Language: Russian

Citation: Mishchik SA (2018) SYSTEMIC PROBLEMS OF ELECTROMAGNETIC INDUCTION OF APPLIED PHYSICS MARITIME FLOT OF PEDAGOGOMETRIC ANALYSIS. ISJ Theoretical \& Applied Science, 02 (58): 166-171.

Soi: http://s-o-i.org/1.1/TAS-02-58-35 Doi: crossef https://dx.doi.org/10.15863/TAS.2018.02.58.35
\end{abstract}

УДК 372.851

\section{СИСТЕМНЫЕ ЗАДАЧИ ЭЛЕКТРОМАГНИТНОЙ ИНДУКЦИИ ПРИКЛАДНОЙ ФИЗИКИ МОРСКОГО ФЛОТА ПЕДАГОГОМЕТРИЧЕСКОГО АНАЛИЗА}

Аннотация: рассмотрены основные принцииы построения системных задач электромагнитной индукции прикладной физики морского флота педагогометрического анализа при формировании математических моделей учебной деятельности относительно характера достижения критериев жизнедеятельности, ичиклиности, систелности и этапности, которые образуют базисную ячейку образовательного пространства, а также применение двенадиати конечной звезды Эригаммы относительно представления приничипа эригаммности, который определит основы педагогометрики через формообразование предметными методами гиперпространства профессиональной жизнедеятельности, психолого-педагогической теории деятельности, психолого-педагогического системного анализа и теории формирования умственных действий.

Ключевые слова: педагогометрика, жизнедеятельность, ичикличность, системность, этапность, звезда Эригаммы, электромагнитная индукияя, прикладная физика, морской флот.

\section{Introduction}

Построение системных задач электромагнитной индукции прикладной физики морского флота педагогометрического анализа связывается с решением проблемы формирования математических моделей учебной деятельности через критерии жизнедеятельности, цикличности, системности и этапности. При этом формируется базисная ячейка образовательного пространства, которая отражает структуру двенадцати конечной звезды Эрцгаммы относительно представления принципа эрцгаммности. Установленная закономерность задаёт основы педагогометрики через представление предметных методов гиперпространства профессиональной жизнедеятельности, психолого-педагогической 
теории деятельности, психолого-педагогического системного анализа и теории формирования умственных действий $[1,2,3]$.

Данные условия направлены на совершенствование базы предметных прикладных профессиональных задач отражающих целостную профессиональную деятельность на морском флоте. Построенные математические модели учебнопрофессиональной деятельности связываются с: базисной звездой Эрцгаммы гиперпространства жизнедеятельности (Е1); базисным целостносистемным циклом жизнедеятельности (Е2); базисной звездой Эрцгаммы системного анализа (E3); базисным проявлением двенадцати этапов и форм познавательного гиперпространства жизнедеятельности относительно образовательного процесса (E4) $[4,5,6]$.

Проектирование заданной базы предметных педагогометрических моделей эрцгаммного анализа образовательных объектов с признаком базисно-нормативной эрцгаммности, независимо от целевого назначения, выполняет собственную функцию психолого-математического представления профессионально-значимых объектов через единство признаков смыслообразования учебно-профессионального действия, его принятия, ориентировочноисполнительно-контрольных признаков и прогноза совершенствования анализа объектов педагогометрческого содержания [7,8,9].

\section{Materials and Methods}

Системные задачи электромагнитной индукции прикладной физики морского флота отражают целостно-системное моделирование основных элементов транспортных объектов. При этом возникает ориентация на единство базисных характеристик предметных и исполнительных условий относительно предмета содержания и способа его реализации. Рассматриваются: магнитные потоки в роторе судового электрического двигателя и судовых электромагнитных датчиках; максимальная электродвижущая сила индукции во вращающейся катушке-роторе судового электрического двигателя; средняя электродвижущая сила, которая индуцируется в датчик-витке связи при отключении соленоида судового электромагнитного автоматизированного контроллера на морском флоте [10, 11,12].

В процессе решения системных задач электромагнитной индукции прикладной физики морского флота необходимо применять основные положения теории деятельности, системного анализа и теории формирования интеллекта.

Системный анализ предполагает выполнение последовательности системных аналитических действий: выделить объект анализа - задачу электромагнитной индукции прикладной физики морского флота (ЗЭМИПФМФ) как систему; установить порождающую среду ЗЭМИПФМФ; определить уровни анализа ЗЭМИПФМФ; представить целостные свойства ЗЭМИ-ПФМФ относительно пространственных, и временных характеристик и их комбинаций; выделить структуру уровня анализа ЗЭМИПФМФ; установить структурные элементы уровня анализа ЗЭМИПФМФ; определить системообразующие связи данного уровня анализа ЗЭМИПФМФ; представить межуровневые связи анализа ЗЭМИПФМФ; выделить форму организации ЗЭМИПФМФ; установить системные свойства и поведение ЗЭМИПФМФ.

\section{Задача 1}

В судовом электрическом двигателе в однородном магнитном поле напряженностью $\mathrm{H}=79,6$ кА/м помещена квадратная рамка ротора, плоскость которой составляет с направлением магнитного поля угол $\alpha=45^{\circ}$. Сторона рамки судового ротора $a=4$ см. Определить магнитный поток $\Phi$, пронизывающий рамку ротора в судовом электрическом двигателе.

Ответ: $\Phi=113$ мкВб.

\section{Задача 2}

В судовом электромагнитном датчике с магнитном полем, индукция которого $\mathrm{B}=0,05$ Тл, вращается индикаторный стержень длиной $\ell=1$ м . Ось вращения, проходящая через один из концов судового индикаторного стержня, параллельна направлению магнитного поля. Найти магнитный поток $\Phi$ в судовом электромагнитном датчике, пересекаемый индикаторным стержнем при каждом обороте.

Ответ: $\Phi=157$ мВб .

\section{Задача 3}

В судовом электрическом двигателе рамка ротора, площадь которой $\mathrm{S}=16 \mathrm{~cm}^{2}$, вращается в однородном магнитном поле с частотой $n=2 \mathrm{c}-1$. Ось вращения находится в плоскости рамки ротора и перпендикулярна к направлению магнитного поля судового электрического двигателя. Напряженность магнитного поля $\mathrm{H}=79,6 \quad$ кА/м. Определить зависимость магнитного потока $\Phi$, пронизывающего рамку ротора, от времени $\mathrm{t}$ и наибольшее значение $\Phi_{\max }$ магнитного потока судового электрического двигателя.

Ответ: $\Phi_{\max }=160$ мВб.

\section{Задача 4}

В судовом электромагнитном датчике круговой проволочный датчик-виток площадью $\mathrm{S}=0,01 \mathrm{M}^{2}$ находится в однородном магнитном 
поле, индукция которого В $=1$ Тл. Плоскость датчика-витка перпендикулярна к направлению магнитного поля. Определить среднюю э. д. с. индукции Есp, возникающую в судовом электромагнитном датчике-витке при выключении поля в течение времени $\mathrm{t}=10$ мс .

Ответ: $\mathrm{Ecp}=1 \mathrm{~B}$.

\section{Задача 5}

В судовом электрическом двигателе в однородном магнитном поле статора, индукция которого $\mathrm{B}=0,1$ Тл, равномерно вращается катушка-ротора, состоящая из $\mathrm{N}=100$ витков, проволоки. Частота вращения катушки-ротора $\mathrm{n}$ $=5 \mathrm{c}^{-1}$; площадь поперечного сечения катушкиротора $S=0,01 \mathrm{~m}^{2}$. Ось вращения перпендикулярна к оси катушки-ротора и направлению магнитного поля судового статора. Определить максимальную э. д. с. индукции $\mathrm{E}_{\max }$ во вращающейся катушке-роторе судового электрического двигателя.

Omвеm: $\operatorname{Emax}=3,14 \mathrm{~B}$.

\section{Задача 6}

В судовом электрическом двигателе в однородном магнитном поле, индукция которого $\mathrm{B}=0,8$ Тл, равномерно вращается ротор-рамка с угловой скоростью $\omega=15$ рад/с. Площадь роторарамки $\mathrm{S}=150 \mathrm{~cm}^{2}$. Ось вращения находится в плоскости ротора-рамки и составляет угол $\alpha=30^{\circ}$ с направлением магнитного поля. Определить максимальную э. д. с. индукции $\operatorname{Emax}$ во вращающейся рамке-роторе судового электрического двигателя.

Ответ: $\operatorname{Emax}=0,09 \mathrm{~B}$.

\section{Задача 7}

В судовом электромагнитном автоматизированном контроллере горизонтальный датчик-стержень длиной $\ell=1$ м вращается вокруг вертикальной оси, проходящей через один из его концов. Ось вращения параллельна магнитному полю, индукция которого $\mathrm{B}=50$ мкТл. При какой частоте вращения $\mathrm{n}$ датчика-стержня в судовом электромагнитном автоматизированном контроллере разность потенциалов на концах этого датчика-стержня $\mathrm{U}=1 \mathrm{MB}$ ?

Ответ: $n=6,4 c^{-1}$.

\section{Задача 8}

В судовом электромагнитном автоматизированном контроллере на соленоиде длиной $\ell=20 \quad$ см и площадью поперечного сечения $\mathrm{S}=30 \mathrm{~cm}^{2}$ установлен проволочный датчик-виток связи. Соленоид состоит из $\mathrm{N}=320$ витков, по которым следует сила тока I=3 А. Определить среднюю э. д. с. Еср , которая индуцируется датчиквитке связи при отключении соленоида судового электромагнитного автоматизированного контроллера в течение времени $\mathrm{t}=1 \mathrm{мc}$.

Oтвет: $\mathrm{Ecp}=18 \mathrm{MB}$.

В $\quad$ удовом Задача 9 автоматизированном контроллере на соленоиде длиной $\ell=20 \quad$ см и площадью поперечного сечения $\mathrm{S}=30 \mathrm{~cm}^{2}$ установлен проволочный датчик-виток связи. Соленоид состоит из $\mathrm{N}=320$ витков, по которым следует сила тока I=3 А. Определить среднюю э. д. с. Еср , которая индуцируется датчик-витке связи при отключении соленоида судового электромагнитного автоматизированного контроллера в течение времени $\mathrm{t}=1$ мс, если соленоид имеет железный сердечник с магнитной проницаемостью $\mu=400$.

Oтвет: $\mathrm{Ecp}=5,1 \mathrm{~B}$.

\section{Задача 10}

В судовом электромагнитном автоматизированном контроллере на соленоиде длиной $\ell=144$ см и диаметром $\mathrm{D}=5$ см установлен проволочный датчик-виток связи. Соленоид состоит из $\mathrm{N}=2000$ витков, по которым следует сила тока I=2 А. Определить среднюю э. д. с. Еср , которая индуцируется датчик-витке связи при отключении соленоида судового электромагнитного автома-изированного контроллера в течение времени $\mathrm{t}=2$ мс, если соленоид имеет железный сердечник с магнитной проницаемостью $\mu=400$.

Ответ: $\mathrm{Ecp}=1,57 \mathrm{~B}$.

\section{Conclusion}

Представленный метод формирования широкопрофильного профессионального мышления связывается с организацией всестороннего развития педагогометрической эрцгаммности. Выделенные системные задачи электромагнитной индукции прикладной физики морского флота педагогометрического анализа отражают основные направления развития и совершенствования базы предметных педагогометрических моделей образовательных объектов относительно педагогометрического математического моделирования учебного процесса. Это связывается с процессами совершенствования программируемых математических моделей учебной деятельности относительно характера достижения критериев жизнедеятельности, цикличности, системности и этапности $[13,14,15]$.

При этом психолого-педагогометрический системный анализ определяет базисную 
методологию и формирует метод представления специалиста широкого профиля - результат практической реализации целостно-системного учебного процесса на примере решения системных задач электромагнитной индукции прикладной физики морского флота. Особенной базисной активностью психологопедагогометриического системного анализа является действие по формированию уровней представления строения электромагнитной индукционной системы.

Процесс формирования уровней строения или анализа физической системы задаётся общим принципом иерархии разложения сложной функции системы на более простые и частичные функции отдельных структурных элементов. При этом можно определить единство противоположных функций: широкопрофильная функция складывается из отдельных частичных операций.

В целом, процесс формирования уровней строения электромагнитной индукционной системы складывается из четырёх основных фазовых состояний системы: 1) разложение общей целостной функции системы на составляющие функции с постепенным расчленением операций на элементарные; 2) определение целостно-системных функций предметных условий каждого цикла жизнедеятельности на любом этапе их представления; 3) выделение целостносистемных функций оперативных условий любого цикла жизнедеятельности на произвольной форме их формирования с заданными характеристиками; 4) обеспечение принципа смещения предметных условий цикла жизнедеятельности при прямом и обратном анализе предметно-структурных элементов процессов воспитания специалистов широкого профиля. Процессы фазового перехода развития циклов определяют мультипликативную форму развития. Рассмотрим эти фазовые состояния.

Процесс разложения общей целостной функции электромагнитной индукционной системы на составляющие функции с постепенным расчленением операций на элементарные под-чиняется общей логике педагогометрического системного анализа, когда на каждом этапе последовательно формируется новое оперативное состояние. При этом сама функция формируется по нейронному принципу с чётким выделением ориентационой, исполнительной и контрольных компонентов отдельной функции - действия. Этот последовательный процес, имея последовательное прохождение через все заложенные функции системы, определяет общую циклическую стратегию перехода от целостных к системным свойствам объекта электромагнитной индукционной системы.

Определение целостно-системных функций предметных условий каждого цикла жизнедеятельности педагогометрического анализа на любом этапе их представления продолжает развитие процесса формирования многоуровневого состояния электромагнитной индукционной системы по предметноструктурным принципам, когда их представление выражается через их многофункциональное состояние, соответствующее базисным формам процесса формирования широкопрофильного педагогометрического мышления. Каждое предметное условие электромагнитной индукционной системы является ориентирующим компонентом соответствующего цикла жизнедеятельности и характер последующего состояния следующих или предыдущих элементов определяется общим технологическим уровнем заданной функции.

Выделение целостно-системных педагогометрических функций оперативных условий любого цикла жизнедеятельности на произвольной форме их формирования с заданными характеристиками устанавливает последовательное функциональное состояния всего цикла жизнедеятельности. Оно задаёт направление базисного функционального состояния цикла электромагнитной индукционной системы, когда множественные системные педагогометрических действия могут приобретать определённые формы процесса заданного поведения цикла. Сложность каждой новой функции электромагнитной индукционной системы направлена на задание начальных условий функционирования предметных условий объектов и установление целостно-системных перспектив их широкопрофильной направленности. Одновременно межфункциональная связь определяет единство типов структур каждого педагогометрического оперативного условия.

Обеспечение принципа смещения предметных условий педагогометрического цикла жизнедеятельности при прямом и обратном анализе предметно-структурных элементов процессов воспитания специалистов широкого профиля задаёт условия динамического поведения цикла жизнедеятельности в направлении его целостного развития при педагогометрическом анализе электромагнитной индукционной системы. Процесс последовательного смещения предметных условий электромагнитной индукционной системы определяется соответствующим ростом педагогометрического цикла. Таким образом возникают рефлексивные схемы функционального состояния системы 
педагогометрических

жизнедеятельностей. В процессе прямого смещения формируются перспективных формы учебной широкопрофильной деятельности. При обратном смещении можно моделировать основные исторические формы учебнопрофессиональной деятельности в новых педагогометрических облачных образовательных технологиях.

Таким образом, многомерное представление циклов учебной жизнедеятельности позволяет сформировать гиперпространства целостносистемных педагогометрических широкопрофильных процессов. Они задают новые дидактические принципы, обеспечивающие педагогометрический анализ всех образовательных процессов. Принцип многоуровневого моделирования задаёт высший уровень педагогометрического мастерства преподавателя, который определяется знанием тщательного представления всей палитры педагогических проблем от вы-деления новых образовательных задач до генерирования интегральных форм целостно-системного моделирования учебно-профессиональной широкопрофильной деятельности. Определение условий эффективной учебно-профессиональной коммуникации учитель-ученик, установление учебных предметных условий, определение системных классов исследовательских задач на условии формирования нормативной творческой деятельности - выделяют абсолютно акмеологические условиях воспитания целостносистемной широкопрофильной личности, способной самостоятельно задавать целостные свойства объекта, выделять его порождающую среду, устанавли-вать уровни строения системы по функциональному и предметному принципу в прямом и обратном развитии системы мира.

Данные процессы образуют базисную ячейку образовательного пространства, а также выражают смысл двенадцати конечной звезды Эрцгаммы относительно представления принципа эрцгаммности. Установленные структуры определяют основы педагогометрики через формообразование предметными методами гиперпространства профессиональной жизнедеятельности, психолого-педагогической теории деятельности, психолого-педагогического системного анализа и теории формирования умственных действий. Представленные критерии жизнедеятельности, цикличности, системности и этапности, которые образуют базисную ячейку образовательного пространства, порождают условия формирования абсолютного образовательного цикла, отражающего специфическую структуру подготовки широкопрофильно-инновационных специалистов при реализации международных образовательных стандартов алигорамной формы эревнометрического содержания.

\section{References:}

1. Mishchik SA (2014) Pedagogometrika and mathematical modeling educational activity. Materialy Mezhdunarodnoy nauchnoy konferenctsii "Modern mathematics in science" - 30.06.2014. ISJ Theoretical \&Applied Science 6(14): 54-56 Caracas, Venezuela. doi: http://dx.doi.org/10.15863/TAS.2014.06.14.10

2. Mishchik SA (2014) Simulation training activity methods of mathematical logic. Materialy Mezhdunarodnoy nauchnoy konferenctsii "Eurapean Science and Education" - 30.07.2014. ISJ Theoretical \&Applied Science 6(15): 72-74 Marseille, France. doi: http://dx.doi.org/10.15863/TAS.2014.07.15.13

3. Mishchik SA (2014) Mathematical modeling system integrity-cycle of life activity - first goal pedagogometriki. Materialy Mezhdunarodnoy nauchnoy konferenctsii "European Applied Sciences" - 30.08.2014. ISJ
Theoretical \&Applied Science 7(16): 77-79. Aix-en-Provence, France. doi: http://dx.doi.org/10.15863/TAS.2014.08.16.13

4. Mishchik SA (2014) Mathematical modeling system integrity-curricular activities - the second problem pedagogometriki. Materialy Mezhdunarodnoy nauchnoy konferenctsii "European Innovation" - 30.09.2014. ISJ Theoretical \&Applied Science 9(17): 126-128 Martigues, France. doi: http://dx.doi.org/10.15863/TAS.2014.09.17.21

5. Mishchik SA (2014) Mathematical modeling holistic-systemic communicative activity - the third task pedagogometriki. Materialy Mezhdunarodnoy nauchnoy konferenctsii "European Scientific Achievements" 30.10.2014. ISJ Theoretical \&Applied Science 10(18): 45-47 Brighton, UK. doi: http://dx.doi.org/10.15863/TAS.2014.10.18.11 


\begin{tabular}{l|lr|ll|ll} 
& ISRA (India) & $=\mathbf{1 . 3 4 4}$ & SIS (USA) & $=\mathbf{0 . 9 1 2}$ & ICV (Poland) & $=\mathbf{6 . 6 3 0}$ \\
Impact Factor: & ISI (Dubai, UAE) $=\mathbf{0 . 8 2 9}$ & PUHЦ (Russia) $=\mathbf{0 . 2 0 7}$ & PIF (India) & $=\mathbf{1 . 9 4 0}$ \\
& GIF (Australia) & $\mathbf{0 . 5 6 4}$ & ESJI (KZ) & $=4.102$ & IBI (India) & $=\mathbf{4 . 2 6 0}$ \\
& JIF & $=\mathbf{1 . 5 0 0}$ & SJIF (Morocco) & $=\mathbf{2 . 0 3 1}$ & & \\
\hline
\end{tabular}

6. Mishchik SA (2014) Mathematical modeling integrity - system performance subject - fourth task pedagogometriki. Materialy Mezhdunarodnoy nauchnoy konferenctsii "Eurapean Science and Technology" 30.11.2014. ISJ Theoretical \&Applied Science 11(19): 51-54 Southampton, UK. doi: http://dx.doi.org/10.15863/TAS.2014.11.19.10

7. Mishchik SA (2015) Pedagogometrik - science and academic subject. Materialy Mezhdunarodnoy nauchnoy konferenctsii "European Technology in Science" 28.02.2015. ISJ Theoretical \& Applied Science 02 (22): 103-106 Malmö, Sweden. doi: http://dx.doi.org/10.15863/TAS.2015.02.22.17

8. Svetlickij V.A. (1994) Zadachi i primery po teorii kolebanij. M.: Izd-vo MGTU im. N.E. Bauma-na, 1994. - p.308.

9. Tokmazov GV (2014) Matematicheskoe modelirovanie $\mathrm{v}$ uchebno-professional'noy deyatel'nosti. Materialy Mezhdunarodnoy nauchnoy konferentsii «Modern mathematics in science» - 30.06.2014. ISJ Theoretical \& Applied Science 6(14): 44-46. - Caracas, Venezuela. doi: http://dx.doi.org/10.15863/TAS.2014.06.14.8

10. Tokmazov GV (2014) Mathematical modeling research skills in educational activity methods of probability theory. Materialy Mezhdunarodnoy nauchnoy konferenctsii "Eurapean Science and Technology" 30.11.2014. ISJ Theoretical \&Applied Science 11(20): 66-69 Southampton, United Kingdom. doi:

http://dx.doi.org/10.15863/TAS.2014.11.19.13

11. Mishhik N.A. (2016) Pravovy'e osnovy' francuzskoj si-stemy' bor'by' s zagryazneniem morya / Nauchny'e issledovaniya: Informaciya, analiz, prognoz [Tekst]: monografiya / [V.E'.Lebedev, A.A.Sviridenko, V.M.Sokolinskij i dr.]; pod obshhej red. prof. O.I.Kirikova - Kniga 51.- Voronezh-Moskva.

12. Mishchik NA (2014) The practice of french justice article 228 of the UN convention on the law of the sea. Materialy Mezhdunarodnoy nauchnoy konferenctsii "The European Science and Education"- 30.07.2014. ISJ Theoretical \& Applied Science 07 (15): 93-97. - Marseille, France.

doi: http://dx.doi.org/10.15863/TAS.2014.07.15.19

13. Mishhik N.A., Antonenko G.A. (2013) Liniya gorizonta kak gradientny'j perepad $\mathrm{V}$ fotograficheskix izmereniyax dlya celej morexodnoj astronomii//E'kspluataciya morskogo transporta. 2013. № 2 (72). Novorossijsk, p. 23-28.

14. Mishhik, N.A. (2000) Optimizaciya metodov morexodnoj astronomii [Tekst]: avto-ref.dis. ... kand. tex. nauk: 05.22.16 / N.A.Mishhik. Novorossijsk, 2000. -24 p.

15. Mishhik, N.A. (2000) Optimizaciya metodov morexodnoj astronomii [Tekst]: dis. ... kand. tex. nauk: 05.22.16 / N.A.Mishhik. Novorossijsk, 2000. - 188 p. 